\title{
УДК 371.3:612.013-027.45 \\ МЕТОД КЕЙСОВ КАК ЭФФЕКТИВНАЯ ОБРАЗОВАТЕЛЬНАЯ ТЕХНОЛОГИЯ ПРИ ИЗУЧЕНИИ ИНТЕГРИРОВАННОЙ УЧЕБНОЙ ДИСЦИПЛИНЫ «БЕЗОПАСНОСТЬ ЖИЗНЕДЕЯТЕЛЬНОСТИ ЧЕЛОВЕКА»
}

\begin{abstract}
Дюбкова Т.П.
В статье представлен опыт обучения студентов посредством метода кейсов при освоении содержания дисциплины «Безопасность жизнедеятельности человека» в Белорусском государственном университете. Метод кейсов использован для развития у студентов способностей к анализу чрезвычайной ситуации, поиску оптимального паттерна поведения и формирования мотивации к повышению уровня физической культуры. Установлено, что высокий уровень физической подготовленности, развитие эмоционально-волевых и нравственных качеств, способности к самоконтролю и саморегуляции поведения являются дополнительным ресурсом выживания человека в чрезвычайных ситуациях природного и техногенного характера.
\end{abstract}

Ключевые слова: безопасность жизнедеятельности человека, чрезвычайная ситуация, паттерн поведения, метод кейсов, студенты, мотивация, физическая культура.

\section{(Поступила в редакцию 5 октября 2016 г.)}

Введение. Реализация компетентностной модели подготовки специалиста требует внедрения в образовательный процесс инновационных технологий, обеспечивающих его личностно-ориентированный и проблемно-исследовательский характер, а также модернизации программно-методического и дидактического оснащения, направленного на повышение качества обучения и роли самостоятельной работы студентов. На современном этапе в качестве эффективных образовательных технологий выступают технологии проблемномодульного обучения, коммуникативные, проектные, кейс-технологии, исследовательские методы. При организации в учреждениях образования практических и семинарских занятий предпочтение отдается развивающим технологиям, основанным на рефлексивнодеятельностных формах и методах обучения (мозговой штурм, игровые методы, дискуссия, пресс-конференция, метод кейсов, учебные дебаты, круглый стол) [3]. Цель технологий развивающего обучения - всестороннее гармоничное развитие личности, при этом знания выступают в качестве средства достижения этой цели.

Основная часть. Цель paботы - представить опыт использования метода кейсов при изучении дисциплины «Безопасность жизнедеятельности человека» для развития у студентов способностей к анализу чрезвычайной ситуации, поиску оптимального паттерна поведения и формирования мотивации к повышению уровня физической культуры.

Учебная дисциплина «Защита населения и объектов от чрезвычайных ситуаций» относится к перечню дисциплин, обязательных для изучения на первой ступени высшего образования (в том числе для непрофильных специальностей), включенных в состав интегрированной учебной дисциплины «Безопасность жизнедеятельности человека». Последняя относится к циклу общепрофессиональных дисциплин (государственный компонент). Цель изучения интегрированной учебной дисциплины в учреждениях высшего образования Республики Беларусь - формирование культуры безопасности жизнедеятельности будущих специалистов, основанной на системе социальных норм, ценностей и установок, обеспечивающих сохранение их жизни, здоровья и работоспособности в условиях постоянного взаимодействия со средой обитания [1].

При изучении студентами дисциплины «Безопасность жизнедеятельности человека» в образовательный процесс автором были внедрены различные активные методы обучения: метод кейсов (case-study, или метод конкретных ситуаций), «мозговой штурм» («мозговая атака»), открытая дискуссия. Case-study - интерактивный метод, основанный на обучении путем решения конкретных ситуаций (кейсов) [2]. Метод кейсов использован при освоении содержания модуля 1 «Организация защиты населения и объектов от чрезвычайных ситуаций природного и техногенного характера, опасностей военного времени» типовой учебной программы «Безопасность жизнедеятельности человека». Целевая аудитория - студенты 1-го курса гуманитарных специальностей Белорусского государственного университета (81 чел.). Успешная реализация метода предусматривала распределение студентов на под- 
группы по 10-15 человек (оптимальное количество). Вид занятий в каждой подгруппе практическое занятие продолжительностью 2 академических часа.

Основные задачи, решаемые в процессе реализации метода кейсов при изучении вышеназванной дисциплины, систематизированы следующим образом:

1) развитие у студентов умений и навыков мыслительной деятельности, обобщения информации и вычленения в ее структуре главного и второстепенных компонентов, развитие умений работать в команде, способностей аргументировать и отстаивать собственную точку зрения, слушать и учитывать альтернативное мнение;

2) формирование отношения к человеческой жизни как наивысшей ценности;

3) развитие способностей к анализу ситуации, поиску рационального решения проблемы, обоснованного алгоритма действий и оптимальной модели поведения в чрезвычайной ситуации;

4) формирование адекватных представлений о роли физической подготовки как дополнительного ресурса выживания в чрезвычайных ситуациях, сопряженных с высоким риском для жизни и здоровья.

Оперативным источником материала для кейсов служили интернет-ресурсы. В качестве содержательно-информационных средств использовались учебные видеоматериалы (учебный видеокейс) или фрагменты документальных фильмов, основанных на реальных чрезвычайных ситуациях, связанных с опасными природными явлениями, стихийными бедствиями или техногенными катастрофами (землетрясение, пожар в многоэтажном здании, лесной пожар, транспортная авария/катастрофа). Продолжительность видеофильма составляла в среднем 7-9 минут (не более 10 минут). В случае необходимости для предотвращения искажения первичной информации при ее анализе и исключения ошибок при принятии решения студентам была предоставлена возможность повторного просмотра видеоматериалов. Структура учебного видеокейса предполагала наличие не только сюжетной части, но и информационной, позволяющей правильно понять развитие событий, а также методической части, включавшей четкую формулировку задания по анализу кейса для студентов, потенциальных вопросов для дискуссии и презентации, записку для преподавателя. В зависимости от характера сюжетной части формулировалась цель кейса - обучение студентов алгоритму принятия адекватных решений в зоне стихийного бедствия, катастрофы или поиск оптимальных путей выхода из чрезвычайной ситуации, требовавших тщательно продуманных действий, направленных на выживание и сохранение здоровья.

Традиционная схема решения кейса включала 5 этапов: 1) знакомство с чрезвычайной ситуацией, ее источником и причинами возникновения; 2) выделение основной проблемы (или проблем), выявление основных видов опасности для жизни и здоровья людей; 3) генерация идей для «мозгового штурма»; 4) анализ последствий принятия решения или предложенных путей выхода из зоны бедствия; 5) собственно решение кейса - предложение одного или нескольких оптимальных вариантов поведения, оценка альтернатив, указания на возможные сопутствующие проблемы, пути предотвращения их возникновения или способы устранения.

Элемент новизны решения кейса состоял в том, чтобы, войдя в его ситуационный контекст и подвергнув «лавину» идей творческому анализу с целью поиска конструктивного решения проблемы, дать сравнительную оценку паттерну поведения в чрезвычайной ситуации людей, обладающих различным уровнем физической подготовленности, отличающихся степенью выраженности эмоционально-волевых и нравственных качеств, способностью к самоконтролю поведения. Уровень физической подготовленности оценивался по критериям выносливости, быстроты реакции, силы, ловкости, степени развития двигательных навыков. Методическая часть кейса была дополнена расшифровкой соответствующих терминов и понятий, имеющих отношение к физической культуре личности. В нее был включен перечень жизненно важных двигательных навыков и физических упражнений, обеспечивающих их формирование [4], а также наглядный материал в форме мультимедиа. Для успешной реализации сформированных навыков в условиях чрезвычайной ситуации в методической части кейса были рекомендованы следующие приемы: при необходимости объединение отдельных физических упражнений в комплексы; усложнение их такими элементами, как наличие препятствий, помех, отвлекающих факторов; оценка возможности выполнения упражнений на уменьшенной площади опоры, в условиях повышенного риска для жизни и др. 
Для обсуждения кейса и анализа идей с целью поиска конструктивного решения проблемы использован метод «мозговой атаки» («мозговой штурм»). Непременным условием активизации умственной деятельности студентов, плодотворной творческой работы и создания благоприятной психологической обстановки было исключение качественной оценки выдвигаемых идей и критических замечаний как со стороны сверстников, так и педагога. На этапе анализа чрезвычайной ситуации и поиска оптимальных путей выхода из нее студентам предоставлялась полная свобода творчества с поощрением любого количества предлагаемых идей, возможностью их комбинации, улучшения, отрицания и видоизменения. Интерактивная образовательная технология позволяла вовлечь в процесс генерирования идей всех студентов подгруппы независимо от объема теоретических знаний, психологических особенностей и социального статуса каждого участника. Все предложенные идеи записывались в протокольный список. Когда поток идей иссяк, начался их творческий анализ. Конечным результатом коллективной работы явилась соответствующая уровню физической подготовленности модель поведения людей в чрезвычайной ситуации природного или техногенного характера, а также возможные оптимальные пути выхода, требующие четкого алгоритма действий в связи с наличием угрозы для жизни и здоровья.

Следующий этап - публичное представление (презентация) результатов анализа кейса и спровоцированная докладчиком дискуссия. Поводом для дискуссии стал неодинаковый паттерн поведения в чрезвычайной ситуации людей, обладающих различным уровнем физической подготовленности, степенью развития эмоционально-волевых и нравственных качеств, самоконтроля поведения. В завершение процесса обучения каждый участник получил задание по подготовке индивидуального письменного анализа кейса. Содержательная активность студента в открытой дискуссии и/или устном представлении результатов анализа и письменный отчет-презентация послужили основой для формирования итоговой оценки. В контексте сюжетной части кейса и основной проблемы, подлежащей решению в процессе «мозгового штурма», студентам было предложено разработать рекомендации по организации мер, способствующих повышению привлекательности физической активности для молодежи.

Групповой разбор кейса потребовал кооперации усилий всех членов команды и активной творческой работы каждого участника. Достоинством метода кейсов при освоении содержания модуля учебной дисциплины «Безопасность жизнедеятельности человека» явилось развитие у студентов коммуникативных навыков, культуры общения, способности к анализу ситуации и поиску рационального решения проблемы. Следует отметить также развитие способности воспринимать и оценивать информацию, поступающую одновременно по разным каналам (зрительному, слуховому анализаторам) и в разных формах (вербальной, невербальной). Важным результатом коллективной работы явилось приобретение участниками обсуждения опыта преодоления препятствий при поиске путей выхода из чрезвычайной ситуации, формирование способности принимать на себя ответственность за решения в условиях неопределенности и высокого риска. В конечном итоге обучающий тренинг посредством метода кейсов позволил выработать у студентов паттерн поведения, направленный на сохранение жизни и здоровья, осуществимый в случае необходимости в реальной чрезвычайной ситуации природного или техногенного характера.

Анализ кейса показал, что набор стереотипных реакций, характер и последовательность адекватных действий в значительной мере определяются жизненно важными двигательными навыками, приобретенными ранее, и существенно отличаются у людей с различным уровнем физической подготовленности. Необходимость быстрого реагирования на любой вид опасности источника чрезвычайной ситуации требует мгновенной мобилизации физических ресурсов организма, чтобы совершать ряд своевременных адекватных действий, направленных на выживание. По данным литературы, почти 99,0 \% людей, внезапно оказавшихся в ситуациях, угрожающих жизни, испытывают в течение первых минут страх и растерянность. В случае отсутствия физической и психологической готовности они не способны к активным действиям по спасанию собственной жизни в течение длительного промежутка времени, что может привести к неблагоприятным последствиям. Единственный путь к победе над страхом и сохранению работоспособности - соответствующая подготовка. Она включает превентивное обучение целенаправленному проявлению деятельности в условиях, сопряженных с опасностью для жизни и здоровья. Приобретение навыков поведения требует многократного повторения и закрепления определенных действий. Так, для выживания в природной чрезвычайной ситуации, источником которой являются гео- 
логические процессы (землетрясение, оползень), необходимы навыки быстрого передвижения между препятствиями, навыки преодоления горизонтальных и вертикальных препятствий, а также соскакивания с препятствий и сооружений (прыжки в глубину). Совершенствование этих навыков достигается с помощью таких упражнений, как «слаломный» бег между стойками, бег «змейкой», лазание по канату без помощи ног или перелезание с каната на канат, запрыгивание на препятствие и спрыгивание с него [4]. В случае обрушения поврежденных строительных конструкций и образования завалов для спасения собственной жизни или жизни находящихся под обломками здания людей требуется тщательно отработанная техника перелезания (переползания) через различные препятствия. С этой целью в ходе специальных физических упражнений приобретаются навыки пролезания, подлезания, передвижения и переползания в условиях малой высоты, в узких проходах. Отсутствие таких навыков у человека с недостаточной физической подготовленностью уменьшает его шансы на выживание в чрезвычайной ситуации. Для того чтобы быстро покинуть горящее многоэтажное здание, необходимо заблаговременно развивать и совершенствовать координационные способности (ходьба по бревну с переноской партнера, серийные прыжки через барьеры с ведением мяча и др.), приобретать навыки равновесия и передвижения по ограниченной опоре, навыки перелезания через различные препятствия. Чрезвычайная ситуация, источником которой является лесной пожар, требует от человека развития выносливости и совершенствования скоростных способностей. Они достигаются с помощью физических упражнений, основу которых составляет бег (с максимальной частотой движений в упоре стоя, с максимальной скоростью при незначительном периоде отдыха).

Систематическое выполнение физических упражнений содействуют реализации внутреннего потенциала организма и позволяют достигнуть физического совершенства, необходимого для выполнения адекватных действий в любой ситуации, сопряженной с риском для жизни. Они способствуют также формированию эмоционально-волевых и нравственных качеств личности. Физически подготовленный человек отличается выраженным самообладанием и высокой эмоциональной устойчивостью. Самообладание связано с самоконтролем и саморегуляцией эмоционального поведения, с ограничением эмоционального реагирования на источник чрезвычайной ситуации или отдельный психотравмирующий фактор. Оно включает в себя различные волевые качества, в том числе выдержку, смелость и отчасти решительность. Для решительных людей характерно минимальное время принятия жизненно важного решения в ситуациях высокого риска. Промедление с принятием такого решения либо его отсутствие может иметь крайне неблагоприятные последствия как для самого человека, так и для социального окружения. Физически неподготовленные лица отличаются, наоборот, эмоциональной неустойчивостью и склонны к массовым паническим реакциям. Следовательно, высокая физическая активность позволяет не только повысить уровень физической подготовленности, но и сформировать определенные волевые и нравственные качества личности, создать собственную систему жизненных ценностей и установок.

Предложения по организации мер, способствующих повышению привлекательности физической активности для молодежи, были дополнены и систематизированы автором статьи по трем основным направлениям:

а) создание благоприятных условий для занятий физической культурой и спортом: доступность объектов физической культуры и спорта и приближение их к местам проживания студентов, современное оснащение и безопасное оборудование спортивных сооружений, невысокая стоимость организованных занятий спортом, свобода выбора привлекательного вида спорта, популяризация езды на велосипеде и ходьбы пешком как наиболее полезных в экологическом и социальном плане способов отдыха и передвижения, организация велосипедных маршрутов и пеших троп здоровья;

б) психологический комфорт : высокая культура проведения спортивных и оздоровительных мероприятий, соответствующая квалификация тренеров и инструкторов, креативность преподавателей по физической культуре в учреждениях образования, учет интересов молодых людей, занимающейся спортом, адаптация физических нагрузок к состоянию здоровья и уровню физической подготовки, дружественная обстановка и атмосфера сотрудничества в спортивных залах, клубах и центрах;

в) удовлетворенность результатами физической активности. Свобода выбора привлекательного вида спорта, использование специальных комплексов упражнений, адаптированных к индивидуальным физическим возможностям и состоянию здоровья студента, 
стимулируют развитие определенных двигательных навыков и умений владеть своим телом, повышают самооценку и формируют уверенность личности в себе. Осознание достигнутого прогресса в собственном развитии способствует получению удовольствия от физической активности и сохранению мотивации к занятиям физической культурой и спортом как в ближайшей, так и отдаленной перспективе.

Заключение. Метод кейсов является эффективной образовательной технологией при освоении содержания интегрированной учебной дисциплины «Безопасность жизнедеятельности человека». Обучение посредством метода кейсов развивает у студентов способность к анализу ситуации, формирует умения выявлять опасные факторы источника чрезвычайной ситуации и предотвращать их воздействие на организм благодаря тщательно продуманной стратегии поведения, имитирует механизм принятия решений в условиях неопределенности и высокого риска для жизни, формирует мотивацию к физическому совершенствованию. Высокий уровень физической подготовленности (выносливость, быстрота реакции, сила, ловкость, развитие двигательных навыков и др.), развитие эмоционально-волевых и нравственных качеств, способности к самоконтролю и саморегуляции поведения являются дополнительным ресурсом выживания человека в чрезвычайных ситуациях природного и техногенного характера. Естественное стремление человека выжить в условиях чрезвычайной ситуации, сопряженной с высоким риском для жизни и продемонстрированной студентам на примере учебного видеокейса, является мощным побудительным стимулом к развитию и совершенствованию жизненно необходимых двигательных навыков. В свою очередь, формирование у студентов устойчивой мотивации к физическому совершенствованию при обучении посредством метода кейсов является определяющим фактором для повышения уровня физической культуры. Следовательно, кейс выполняет не только обучающую нагрузку, при его решении достигается также воспитательный эффект. Реализация личностно-ориентированного подхода к повышению уровня физической культуры студентов классического университета предусматривает создание благоприятных условий для занятий физической культурой и спортом, психологический комфорт при их проведении, развитие удовлетворенности результатами физической активности.

\section{ЛИТЕРАТУРА}

1. Безопасность жизнедеятельности человека : типовая учеб. программа для учреждений высшего образования, рег. № ТД-ОН.006/тип.: утв. М-вом образования Респ. Беларусь 08 июля 2013 г. / Белорус. гос. ун-т ; авт.-сост. В.Е. Гурский [и др.]. - Минск : РИВШ, 2013. - 34 с.

2. Долгоруков, А. Метод case-study как современная технология профессиональноориентированного обучения [Электронный ресурс] / А. Долгоруков. - Режим доступа : http://pycode.ru/2012/05/case-study/, свободный - Дата доступа : 29.02.2016.

3. Жук, О.Л. Педагогическая подготовка студентов : компетентностный подход / О.Л. Жук. Минск : РИВШ, 2009. - 336 с.

4. Приешкина, А.Н. Содержание и методика подготовки учащихся старших классов к действиям в экстремальных ситуациях социального характера : автореф. дис. канд. пед. наук : 13.00 .04 / А.Н. Приешкина. Сибирский гос. ун-т физ. культуры и спорта. - Омск, 2005. 


\section{CASE-STUDY AS EFFECTIVE EDUCATIONAL TECHNOLOGY AT STUDYING INTEGRATED ACADEMIC DISCIPLINE «SAFETY OF HUMAN VITAL ACTIVITY»}

Tatyana Dyubkova, Candidate of Medical Sciences, Associate Professor Belarusian State University, Minsk, Belarus

Purpose. The experience of teaching students of the Belarusian State University based on casestudy when learning the content of the academic discipline «Safety of human vital activity» is presented in this article.

Methods. Instructional videos or fragments of documentaries, based on real natural and technogenic emergency situations, are used as a content-information resource. Case-study is used for the development of students' abilities to analyze an emergency, find the optimal pattern of behavior and form motivation to increase the level of physical culture.

Findings. The element of novelty of the decision of case was in the comparative assessment of the behavior of people with different levels of physical training, differing degrees of severity of emotional and volitional qualities and self-control of behavior in an emergency situation. High level of physical training (endurance, reaction time, strength, agility, improvement of motor skills), development of volitional and moral qualities, ability to self-control and self-regulation of behavior are an additional resource for human survival in natural and technogenic emergency situations.

Application field of research. The need for a rapid response to any kind of danger emergency source requires instant mobilization of the body's physical resources for the survival of the organism. Systematic physical exercise contributes to the implementation of the body's inner potential and allows achieving physical improvement necessary to perform appropriate actions in any situation involving risk to life. It also contributes to the formation of emotional and volitional and moral qualities of the person required for the survival.

Conclusions. Teaching of students through case-study develops ability to analyze the situation, creates the ability to identify emergency source hazards and prevent their effects on the body due to the behavior of an elaborate strategy, imitates the mechanism of decision making under conditions of uncertainty and high risk to life, develops motivation for physical improvement.

Keywords: safety of human vital activity, emergency situation, pattern of behavior, case-study, students, motivation, physical culture.

(The date of submitting: October 5, 2016)

\section{REFERENCES}

1. Gurskiy V.E., Dunay V.I., Dyubkova T.P., Arinchina N.G., Zhadobina L.A., Rudkovskiy P.E. Bezopasnost' zhiznedeyatel'nosti cheloveka [Safety of human vital activity]: tipovaya ucheb. programma dlya uchrezhdeniy vysshego obrazovaniya, reg. No TD-ON.006/tip.: utv. M-vom obrazovaniya Resp. Belarus' 08.07.2013, Belorus. gos. un-t. Minsk: RIVSh, 2013, available at http://elib.bsu.by/handle/123456789/46904 (accessed: January 30, 2016). (rus)

2. Dolgorukov A. Metod case-study kak sovremennaya tekhnologiya professional'no-orientirovannogo obucheniya [Case-study as a modern technology of professional-oriented teaching], available at http://pycode.ru/2012/05/case-study/ (accessed: February 29, 2016). (rus)

3. Zhuk O.L. Pedagogicheskaya podgotovka studentov: kompetentnostnyy podkhod [Pedagogical training of students: competence approach]. Minsk: RIVSh, 2009. 336 p. (rus)

4. Prieshkina A.N. Soderzhanie i metodika podgotovki uchashchikhsya starshikh klassov $k$ deystviyam $v$ ekstremal'nykh situaciyakh social'nogo kharaktera [The content and methods of training of the pupils of higher forms for actions in extreme situations of social character]. Cand. ped. sci. diss. Synopsis: 13.00.04. Sibirskiy gos. un-t fiz. kul'tury i sporta. Omsk, 2005. (rus) 